\title{
Caracterización de los Microorganismos Biodegradadores del Bioplástico de Xiloglucano de Tamarindo en Biorreactores de Compostaje
}

\author{
Characterization of the Biodegrading Microorganisms of the Xyloglucan Plastic \\ of Tamarind in Compostation Bioreactors
}

\author{
P. A. Álvarez-Betancourt iD ; V. M. Luna-Pabello ; ; J. E. Ussa-Garzón iD \\ DOI: https://doi.org/10.22517/23447214.24361 \\ Artículo de investigación científica y tecnológica
}

\begin{abstract}
Resmen - Los plásticos han sido motivo de atención debido a su desmedido uso y acumulación como residuo en los últimos 20 años al ser desechos no biodegradables, por lo cual, los bioplásticos se posicionan como sustitutos alternativos pertinentes por su fácil asimilación por los microoganismos. El objetivo de este estudio fue caracterizar los microorganismos que participaron en la biodegradación de un bioplástico de acrilato de etilo (AE) y xiloglucano de tamarindo (XgT), durante una prueba de biodegradabilidad realizada a través de biorreactores de compostaje, para a su vez reconocer la viabilidad de desarrollo microbiano en tales sistemas de degradación. Para ello, se realizó la siembra primaria en agar sangre y Sabouraud, la siembra secundaria en BHI, medio en el que se diferenciaron 16 morfologías coloniales, con tendencia a bacilos Gram (+); se hizo el perfil enzimático en agar almidón (AA), agar de leche descremada (LD) y agar Baird-Parker (BP) para evidenciar la participación de enzimas amilasa, caseinasa y lecitinasa; asimismo se hizo el análisis cualitativo de degradación y el recuento en placa, el cual mostró un promedio de $2,15 \times 10^{12}$ UFC/ mL de muestra, exhibiendo condiciones para la viabilidad microbiana en los biorreactores de compostaje.
\end{abstract}

Palabras clave - agentes de degradación, bacilos, bioplástico de xiloglucano de tamarindo, biorreactores de compostaje, cultivo bacteriano.

Abstract-Non-biodegradable waste such as plastic has been the subject of attention due to its excessive use and accumulation

Este manuscrito fue enviado el 29 de mayo de 2020 y aceptado 20 de junio 2021. . Este trabajo no tuvo apoyo financiero.

P. A. Álvarez-Betancourt, Ingeniera Ambiental, Universidad Distrital Francisco José de Caldas, Carrera 5 este $\mathrm{N}^{\circ} 15-82$, Bogotá, Colombia, (paalvarezb@correo.udistrital.edu.co).

V. M. Luna-Pabello, Profesor de Carrera Titular "C" de tiempo completo definitivo, PRIDE "C", SNI nivel I, adscrito al Laboratorio de Microbiología Experimental del Departamento de Biología de la Facultad de Química de la UNAM., Torre de Ingeniería, Ala Sur, Piso 6, Cubículo, DF 1 04510, Ciudad de México, México. (lpvictor@unam.mx)

J. E. Ussa-Garzón, Profesor Asistente, Universidad Distrital Francisco José de Caldas, Carrera 5 este $\mathrm{N}^{\circ} 15-82$, Bogotá, Colombia (jeussag@udistrital.edu.co) as waste in the last 20 years, for which reason, bioplastics are positioned as relevant alternative substitutes for their easy assimilation by micro-microorganisms. The objective of this study was to characterize the microorganisms that participated in the biodegradation of a bioplastic of ethyl acrylate (AE) and tamarind xyloglucan (XgT), during a biodegradability test carried out through composting bioreactors, in order to recognize the viability of microbial development in such degradation systems. For this, primary seeding was performed on blood agar and Sabouraud, secondary seeding in IHB, medium in which 16 colonial morphologies were differentiated, with a tendency to Gram (+) bacilli; The enzymatic profile was made on starch agar (AA), skim milk agar (LD) and Baird-Parker agar (BP) to show the participation of enzymes amylase, caseinase and lecithinase; Likewise, the qualitative analysis of degradation and the plate count were made, which showed an average of $2.15 \times 10^{12}$ CFU / mL of sample, exhibiting conditions for microbial viability in composting bioreactors.

Index Terms - degradation agents, bacillus, tamarind xyloglucan bioplastic, composting bioreactors, bacterial culture.

\section{INTRODUCCIÓN}

$\mathrm{E}$ L extendido uso del plástico petroquímico a nivel global tanto de productos básicos como de alto rendimiento, ha traído impactos ambientales negativos al tener tiempos de biodegradación cercanos a los mil años y acumularse en componentes como el agua y el suelo, afectando la calidad y supervivencia de los ecosistemas. Para prevenir tales afectaciones, se han desarrollado sustitutos biodegradables basados en compuestos naturales para lograr una mejor asimilación por los microorganismos [1].

En el 2014, la producción de bioplásticos registrada en el mundo fue de 1,70Mt y se estimó en 6,20Mt para 2018 [2]. Dentro de los bioplásticos se encuentran los obtenidos a partir de monómeros bio-derivados, como el ácido poliláctico (PLA), los producidos por los organismos, como los polihidroxialcanoatos (PHA) y los extraídos directamente de la biomasa como los basados en almidón y celulosa [3]. Dentro de los últimos se incluye el bioplástico de este estudio 
sintetizado de acrilato de etilo y polvo de semilla de tamarindo (b-XgT).

Comúnmente, son llamados 'bioplásticos' aquellos plásticos que poseen una fracción biológica, pero este aspecto no se relaciona con su biodegradabilidad directamente [4], ya que también pueden poseer una fracción petroquímica o ser elaborados de polímeros persistentes por sus interacciones moleculares complejas, como la lignina. Por su parte, el b$\mathrm{XgT}$ es de base biológica y es biodegradable de tipo compostable, así como otros plásticos de polímeros naturales como el PHA y el PLA.

La biodegradabilidad de un compuesto depende de la superficie expuesta al medio, la cantidad de humedad, el peso molecular, la estructura química, la cristalinidad, entre otras propiedades físicas y químicas del compuesto [5].

La capacidad de los polímeros para degradarse depende a su vez de los microorganismos disponibles en los componentes (agua, suelo, compost) a los que son expuestos y la disponibilidad de nutrientes para su supervivencia; en el caso del compost como medio de degradación, es determinante el tipo y composición de los desechos descompuestos o fuentes de carbono disponibles [5]. En general, el compost adecuadamente procesado contiene una alta diversidad de microorganismos degradantes dadas las condiciones ambientales apropiadas para su desarrollo [2].

Este estudio se enfocó en caracterizar las especies microbianas participantes durante el proceso experimental del estudio de evaluación de biodegradabilidad del b-XgT, en vista de las condiciones anaerobias termofílicas presenciadas que no son comunes en este tipo de estudios. Los procedimientos desarrollados en la investigación corresponden a aspectos primordialmente relacionados con la asimilación de nutrientes por parte de los microorganismos.

\section{MATERIALES Y MÉTODOS}

Los métodos utilizados para la caracterización de microorganismos se fundamentaron en los medios de cultivo y observación del desarrollo microbiano en ellos por las diferentes vías metabólicas:

\section{A. Siembra primaria}

Se preparó en la campana de flujo laminar Steril GARD III Advance el agar sangre como medio enriquecido para bacterias y el agar Sabouraud para hongos o bacterias acidófilas,

Para la siembra, se extrajo una pequeña fracción del biorreactor 'Muestra 1' en el día 13 del desarrollo experimental de la evaluación de biodegradabilidad del b$\mathrm{XgT}$, y se sembró por estría por agotamiento en cinco fases en agar sangre y Sabouraud. Se incubó por 24 horas a $36{ }^{\circ} \mathrm{C} \pm 1$ ${ }^{\circ} \mathrm{C}$.

Luego del desarrollo, para diferenciar las morfologías coloniales, se empleó el sistema de imágenes para laboratorio, MultiDoc-It Digital Imaging System, UPV. Se identificó en el agar sangre la existencia de $\alpha$-hemólisis (halo verde), $\beta$ hemólisis (lisis de eritrocitos, halo claro) y $\gamma$-hemólisis (ausencia de halo) y los diferentes desarrollos en el agar Sabouroud.

\section{B. Siembra secundaria}

Se preparó el medio de cultivo enriquecido infusión cerebro-corazón (BHI, por sus siglas en inglés) distribuido en 30 placas Petri en campana de flujo laminar SterilGARD III Advance. Posteriormente, se hizo el aislamiento de las colonias diferenciadas en el anterior procedimiento en cada placa Petri de BHI mediante siembra por estría por agotamiento en cinco fases. Se incubaron a $36{ }^{\circ} \mathrm{C} \pm 1{ }^{\circ} \mathrm{C}$ y se hicieron las descripciones de su desarrollo a las $24 \mathrm{~h}$ y a las $48 \mathrm{~h}$.

\section{Morfología celular bacteriana}

A partir de la realización de la tinción diferencial de Gram de las colonias desarrolladas en BHI, se observó cada una en el microscopio objetivo 100x. Se identificó la tipología Gram y se hicieron las respectivas descripciones de la morfología celular.

\section{Perfil enzimático}

De las colonias desarrolladas en BHI (siembra secundaria), se realizaron siembras en agar almidón (AA), leche descremada (LD), y Baird Parker (BP), para evidenciar la actividad de las enzimas amilasa, caseinasa y lecitinasa. Se realizaron siembras en línea en cuatro cuadrantes y se incubaron por $24 \mathrm{~h}$ a $36{ }^{\circ} \mathrm{C} \pm 1{ }^{\circ} \mathrm{C}$. La actividad amilolítica fue revelada con gotas de Lugol, la caseinolítica y de lecitinasa, a través del desarrollo y lisis de los medios.

\section{E. Evaluación cualitativa}

Consistió en un montaje de sistemas de biodegradación en medio mineral (MM) para observar los cambios del b-XgT en medio líquido. Se preparó el MM con los compuestos que exhibe la Tabla I según estándar de trabajo del Laboratorio de Microbiología Experimental de la Universidad Nacional Autónoma de México (UNAM):

TABLA I.

SUSTANCIAS DEL MEDIO MINERAL (MM) EMPLEADO

\begin{tabular}{|c|c|c|c|c|}
\hline Sustancia & "a" & "b" & "c" & "d" \\
\hline $\begin{array}{l}\text { Contenid } \\
\mathrm{o}\end{array}$ & $\begin{array}{l}\cdot 2,12 \mathrm{~g} \text { de } \mathrm{KH}_{2} \mathrm{PO}_{4} ; \\
\bullet 7,12 \mathrm{~g} \text { de } \mathrm{K}_{2} \mathrm{HPO}_{4} ; \\
\bullet 6,66 \mathrm{~g} \text { de } \\
\mathrm{NaHPO}_{4} \cdot 2 \mathrm{H}_{2} \mathrm{O} \text { o } \\
10,29 \mathrm{~g} \text { de } \mathrm{NaHPO}_{4} \\
4 \mathrm{H} 2 \mathrm{O} ; \cdot 0,17 \mathrm{~g} \mathrm{de} \\
\mathrm{NH}_{4} \mathrm{Cl} \text {. } \\
\mathrm{Se} \text { disolvieron en } \\
\text { agua destilada y se } \\
\text { aforó a } 250 \mathrm{~mL} . \mathrm{Se} \\
\text { midió el pH, y se } \\
\text { ajustó a } 7,4 .\end{array}$ & $\begin{array}{l}1,37 \mathrm{~g} \text { de } \\
\mathrm{CaCl}_{2} \text { o } \\
1,82 \mathrm{~g} \text { de } \\
\mathrm{CaCl}_{2} \\
\cdot 2 \mathrm{H}_{2} \mathrm{O} . \\
\text { Disueltos } \\
\text { en agua } \\
\text { destilada y } \\
\text { aforado a } \\
50 \mathrm{~mL} .\end{array}$ & $\begin{array}{l}1,12 \mathrm{~g} \mathrm{de} \\
\mathrm{MgSO}_{4} \cdot 7 \mathrm{H} \\
2 \mathrm{O} . \\
\text { Disuelto en } \\
\text { agua } \\
\text { destilada y } \\
\text { aforado a } \\
\text { 50mL. }\end{array}$ & $\begin{array}{l}0,012 \mathrm{~g} \mathrm{de} \\
\mathrm{FeCl}_{2} \cdot 6 \mathrm{H}_{2} \mathrm{O} \\
\text { Disuelto en } \\
\text { agua } \\
\text { destilada y } \\
\text { aforado a } \\
50 \mathrm{~mL} \text {. }\end{array}$ \\
\hline
\end{tabular}

Fuente: Elaboración propia.

Para preparar el MM, se mezclaron 10mL de solución "a" y se añadiendo en orden $1 \mathrm{~mL}$ de solución "b", "c" y "d" y se aforó a 1L. Para los sistemas de degradación, se agregaron 
$100 \mathrm{~mL}$ de MM a 5 matraces (uno con $1 \mathrm{~g}$ de peptona caseína al $1 \%)$ y se esterilizaron en autoclave.

Se esterilizó la solución salina (SS) al 0,85\%, con el fin de realizar la mezcla bacteriana de las cepas desarrolladas en BHI a través de siembra de medio sólido a medio líquido por suspensión bacteriana con el ajuste a la turbidez estándar 0,5 McFarland (tubo criterio). Luego, se hizo el montaje de los sistemas de degradación agregando las sustancias mencionadas en la Tabla II a los matraces con $100 \mathrm{~mL}$ de MM.

TABLA II.

CONTENIDO DE LOS MATRACES PARA CONTEO BACTERIANO.

\begin{tabular}{|c|c|c|c|}
\hline \multirow{2}{*}{ Matraz } & \multirow{2}{*}{ Nombre* } & \multicolumn{2}{|c|}{ Contenido } \\
\hline & & Sustancia para degradar & Agentes degradantes \\
\hline 1 & $\mathrm{M}_{1}$ & $1 \mathrm{~g}$ de biopolímero de & $100 \mu \mathrm{L}$ de cepa de \\
\hline 2 & $\mathrm{M}_{2}$ & XgT y AE a cada uno & $\begin{array}{l}\text { bacterias presentes } \\
\text { en el biorreactor de }\end{array}$ \\
\hline 3 & $\mathrm{Ctrl}(+)$ & $\begin{array}{l}\text { 1g de peptona de caseína } \\
(1 \%)\end{array}$ & $\begin{array}{l}\text { composta con } \\
\text { muestras de }\end{array}$ \\
\hline 4 & Ctrl (-) & $\ldots$ & biopolímero de XgT \\
\hline 5 & Ctrl de MM & $\ldots$ & $\ldots$ \\
\hline
\end{tabular}

* $\mathrm{M}_{1}=$ Muestra 1; $\mathrm{M}_{2}=$ Muestra 2; Ctrl (+) = Control positivo; Ctrl (-) = Control negativo; Control de $\mathrm{MM}=$ Control de medio.

Fuente: Elaboración propia.

Los montajes del sistema de composteo se ubicaron en el agitador orbital con incubación G24 Enviromental Incubator Shaker, a $36{ }^{\circ} \mathrm{C} \pm 1{ }^{\circ} \mathrm{C}$ y se realizaron registros de los cambios del b-XgT hasta que ya no fue perceptible a simple vista.

\section{F. Conteo bacteriano}

Se hizo por duplicado el recuento en placa para reconocer las unidades formadoras de colonias (UFC) por mililitro de muestra. Se preparó el medio de cultivo con 7,05g de Agar de Métodos Estándar (SMA, siglas en inglés, [6]) expone su fundamento) en $300 \mathrm{~mL}$ de agua destilada debidamente esterilizado en el autoclave.

Se extrajo $1 \mathrm{~mL}$ del sistema de degradación de la $\mathrm{M}_{1}$ y $1 \mathrm{~mL}$ de la $\mathrm{M}_{2}$ y se hicieron las 10 diluciones seriadas: $1 \mathrm{~mL}$ de muestra en $9 \mathrm{~mL}$ de SS isotónica al $0,85 \%$ y luego $1 \mathrm{~mL}$ de cada dilución a la siguiente. Posteriormente, se hizo el vertido en placa de las diluciones $1 * 10^{-8}, 10^{-9}$ y $10^{-10} \mathrm{~mL}$ (muestra con SMA) y se incubó a $36{ }^{\circ} \mathrm{C} \pm 1{ }^{\circ} \mathrm{C}$ por $24 \mathrm{~h}$. Una vez hubo desarrollo en las 6 placas del duplicado de muestra, se contaron las cepas con ayuda de contador de colonias tipo Quebec, O.A. Spencer inc DGOFO3 1-232-234. El resultado se expresó en UFC/mL de muestra.

\section{G. Actividad bacteriana de la muestra}

Se realizó una suspensión de $0,15 \mathrm{~g}$ de muestra de $\mathrm{XgT}$ y AE en SS isotónica al 0,85 \% y se extrajo de esta una fracción para ser sembrada por agotamiento por estrías en cinco fases en medio BHI y se incubó por $24 \mathrm{~h}$ a $36{ }^{\circ} \mathrm{C} \pm 1{ }^{\circ} \mathrm{C}$. Se distinguieron las morfologías coloniales, se realizó la respectiva tinción de Gram y se observó en el microscopio.

\section{H. Actividad enzimática en los sistemas de composteo}

Se extrajo una fracción de los biorreactores Control Positivo, Control Negativo, Muestra 1 y Muestra 2, se hizo la dilución en SS isotónica al $0,85 \%$ en concentración 0,5 McFarland. Se sembró cada contenido en estrías de una fase con asas de inoculación plásticas Difco Laboratories de volumen conocido de $1 \mu \mathrm{L}$ en los medios $\mathrm{AA}, \mathrm{LD}, \mathrm{BP}$. Se dejaron en incubación por $24 \mathrm{~h}$ a $36{ }^{\circ} \mathrm{C} \pm 1{ }^{\circ} \mathrm{C}$ y se hicieron lecturas y registros según desarrollo.

\section{Resultados}

En la caracterización microbiana se obtuvo:

\section{A. Siembra primaria}

El desarrollo microbiano en agar Sangre, como se observa en tuvo particularidades como la $\beta$-hemólisis evidenciada en el agar sangre, un signo fundamental de la presencia de ciertos tipos de bacterias. Las bacterias $\gamma$-hemolíticas usualmente corresponden a la mayor variedad de bacterias, tal como se obtuvo en este estudio. No se obtuvieron bacterias $\alpha$ hemolíticas.

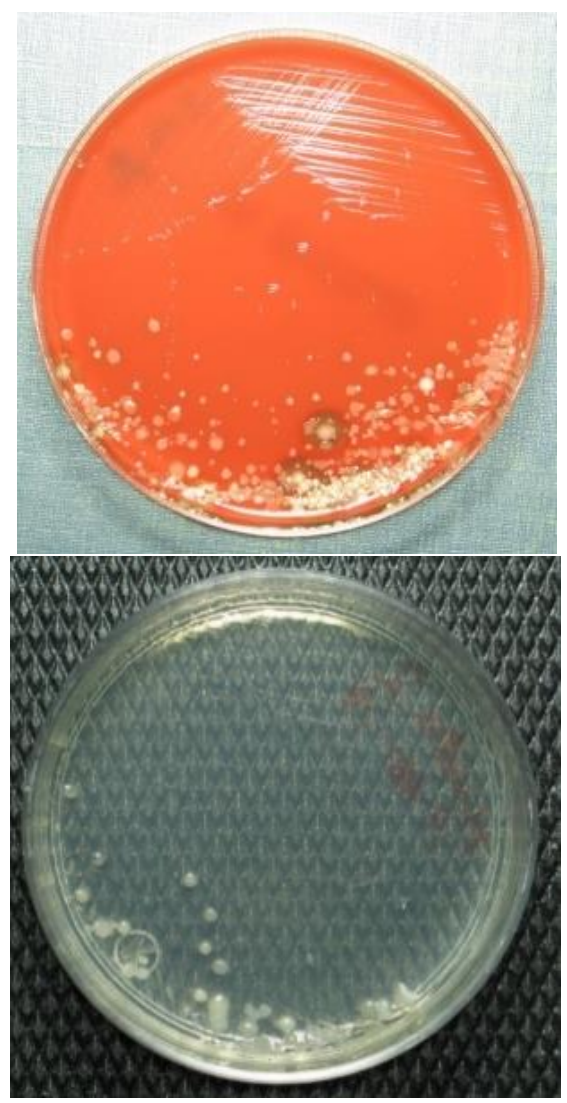

Fig. 1. Crecimiento microbiano en agar sangre (arriba) y Sabouraud (abajo)

Fuente: capturado por autores con el MultiDoc-It Digital Imaging System de la empresa UPV.

Como se observa en la Fig. 1, en el agar Sabouraud, no hubo crecimiento fúngico, sin embargo, si hubo crecimiento 
bacteriano. Las bacterias desarrolladas en este medio son comúnmente filamentosas [7] o pueden tratarse de bacterias con adaptaciones acidófilas dado el $\mathrm{pH}$ de 5.

\section{B. Siembra secundaria}

En este procedimiento 16 colonias tuvieron desarrollo. Sus características son descritas en la Tabla III. Morfología celular bacteriana

Los resultados de la tinción diferencial de Gram y la descripción de las morfologías celulares de las colonias desarrolladas en el agar BHI, son descritos en la Tabla III. La morfología predominante de tipo bacilar, la cual, puede relacionarse al género Bacillus sp.

\section{Perfil enzimático}

En las pruebas con resultado positivo (ver Tabla III), se encontró las actividad de proteasas [8], lo que se relaciona con distintas actividades biotecnológicas. El resultado de amilasa positiva fue obtenido de las cepas $1, \mathrm{~S} 1, \mathrm{~S} 6$ y $\mathrm{S} 4_{\mathrm{B}}$. $\mathrm{La}$ caseinasa, tuvo igualmente el resultado positivo fue para las cepas 1, S1, S6 y S4 $4_{B}$. La cepa con lecitinasa positiva fue únicamente la denominada " 1 ".

TABLA III.

CARACTERIZACIÓN DE CEPAS BACTERIANAS: MORFOLOGÍA COLONIAL Y CELULAR, TINCIÓN DE GRAM Y PRESENCIA DE ENZIMAS.

\begin{tabular}{|c|c|c|}
\hline Cepa & $\begin{array}{l}\text { Morfología colonial } \\
\text { (tamaño/ elevación/ } \\
\text { formal/ borde/ } \\
\text { superficie/ color/ } \\
\text { luz tansmitida/ luz } \\
\text { reflejada }\end{array}$ & \\
\hline $\mathrm{S} 1$ & $\begin{array}{l}\text { Mediano/ plano- } \\
\text { convexas/ circular/ } \\
\text { redondeado/ lisa/ } \\
\text { Blanco navajo/ } \\
\text { Opaca / brillante }\end{array}$ & + \\
\hline $\mathrm{S} 2$ & $\begin{array}{l}\text { Pequeño/ plano- } \\
\text { convexa/ fusiforme/ } \\
\text { redondeado/ lisa/ } \\
\text { caqui/ opaca/ } \\
\text { opaca. }\end{array}$ & + \\
\hline
\end{tabular}

Pequeño/ planoconvexa/ fusiforme/ redondeado/ lisa/ opaca/ opaca.

Mediano/ plana/ circular/
Bacilos/

estreptobacilos/

medianos, gruesos

Se observa un

recubrimiento, por

$(+) \quad(+) \quad(-)$

lo cual se

denominan

"encapsulados".

Bacilos/

alargados, grandes,

gruesos, con la

apariencia de

encadenamiento.

Bacilos/ en "V" y

en empalizada/

gruesos, cortos y

redondeados;

algunas células en

estado de

esporulación.

Bacilos/ en "V" /

bacilos cortos y

delgados.

$(-) \quad(-) \quad(-)$

$(+) \quad(+) \quad(-)$

\begin{tabular}{|c|c|c|c|}
\hline $\begin{array}{l}\text { Tinción } \\
\text { diferencia } \\
1 \text { de Gram } \\
\left(+0_{-}\right)\end{array}$ & $\begin{array}{c}\text { Morfología celular } \\
\text { (forma/ } \\
\text { agrupación/ } \\
\text { descripción) }\end{array}$ & A & $\mathrm{C}$ \\
\hline
\end{tabular}

estreptobacilos/
$(-) \quad(-) \quad(-)$

Mediano/

acuminada/

circular/

S6

redondeado/

rugosa/

Blanquecino-gris/

opaca/ opaca.

Pequeño/ Papilada/

circular/

redondeado/

rugosa/ beige claro/

opaca/ opaca.

Pequeño/ plana/

puntiforme/

2

ondulado/ lisa/ café +

amarillento/

traslúcida/ brillante.

Muy pequeño/

papilada/

puntiforme/

ondulado/ lisa/

beige claro/

traslúcida7

brillante.

Muy pequeño/

plana/ puntiforme/

redondeado/ lisa/

caqui oscuro/

traslúcida/ brillante.

Muy pequeño/

acuminada/

puntiforme/

redondeado/

rugosa/ beige claro/

opaca/ brillante.

Mediano/ plana/

alargada/ ondulado/

12

lisa /amarillo

quemado/traslúcida

/ brillante.

Mediano/ plana/ alargada/ ondulado/

rugosa/ beige

oscuro/ opaca/

opaca.

Muy pequeño/

plana/ fusiforme/

ondulado/ lisa/

beige claro/ opaca/

opaca

Muy pequeños/ papilada/ irregular/ ondulado/rugosa/

beige claro/ opaca/ brillante.
Bacilos/

diplobacilos/

bacilos y en su

mayoría muy

$(+) \quad(+) \quad(-)$

cortos.

Bacilos/ caracteres chinos/; algunos en "V" / medianos y anchos,dan la apariencia de estar encadenados.

Bacilos/ Caracteres chinos/ cortos,

delgados, con apariencia

granular.

(+) (+) (+)

Bacilos/ caracteres chinos/ cortos, gruesos, con aparente estado de esporulación

Bacilos/ estreptobacilos/ bacilos muy delgados, que dan apariencia de cadenas largas.

Bacilos/ en "V"/ cortos y delgados.

$(-) \quad(-) \quad(-)$

Cocos/ estafilococos/ distribuidos irregularmente, son pequeños

Bacilos/ en empalizada/ son bacilos en su mayoría alargados y delgados.

Bacilos/ diplobacilos/son delgados y cortos, su distribución da la apariencia de caracteres chinos.

Forma: bacilos; agrupación: caracteres chinos; descripción: Son bacilos muy cortos, $(-) \quad(-) \quad(-)$
$(-) \quad(-) \quad(-)$

$(-) \quad(-) \quad(-)$ encuentran distribuidos muy irregularmente, 


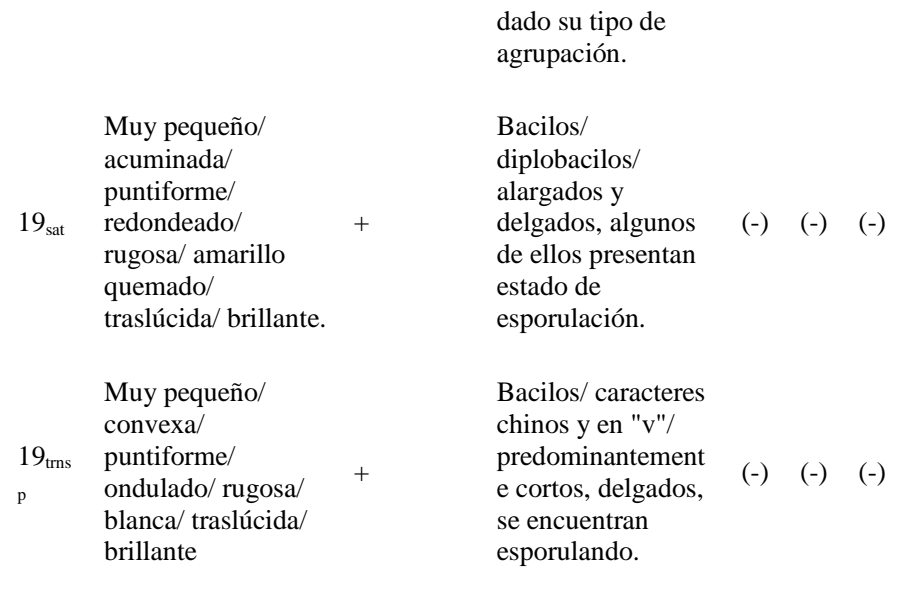

$\mathrm{A}=$ Amilasa; $\mathrm{C}=$ Caseinasa; $\mathrm{L}=$ Lecitinasa.

Fuente: Elaboración propia.

\section{Evaluación cualitativa}

En esta evaluación, se evidenció la actividad de los agentes degradantes a temperatura de $37{ }^{\circ} \mathrm{C}$ y condiciones aerobias, diferente al estudio de biodegradabilidad de biorreactores en donde se encontraban a temperatura de $58{ }^{\circ} \mathrm{C}$ y en anaerobiosis, por lo que dados los resultados de descomposición considerables obtenidos, como se muestra en la TablaIV, si el consorcio bacteriano fue extraído de los mismos biorreactores, pueden tratarse de organismos termófilos y anaerobios facultativos [9].

TABLA IV.

ANÁLISIS CUALITATIVO DE LA DEGRADACIÓN DE LA MUESTRA DE B-XGT.

\begin{tabular}{ll}
\hline \hline Día & \multicolumn{1}{c}{ Descripción } \\
\hline 1 & $\begin{array}{l}\text { En el estado inicial de los sistemas de degradación, se observó la } \\
\text { integridad de la muestra. }\end{array}$ \\
3 & $\begin{array}{l}\text { Se pudo observar un inicio de degradación de } \mathrm{M}_{1}, \mathrm{M}_{2} \text { y el Ctrl (+), } \\
\text { denotado por un aumento de la turbiedad en los matraces de } \\
\text { degradación. El Ctrl (-) y el Ctrl de } \mathrm{MM} \text { no presentan cambios. }\end{array}$ \\
& $\begin{array}{l}\text { Al verificar el paso de luz de los matraces, se observó el aumento } \\
\text { significativo en la turbiedad, una mayor densidad celular por la } \\
\text { actividad bacteriana y partículas aún más pequeñas en el } \mathrm{M}_{1} \text { y } \mathrm{M}_{2} \\
\text { en relación al día anterior. Aun se observan partículas en el fondo } \\
\text { de los matraces de degradación }\end{array}$ \\
& $\begin{array}{l}\text { En los sistemas de degradación } \mathrm{M}_{1}, \mathrm{M}_{2} \text { y del Ctrl (+) aumentó la } \\
\text { turbiedad. En el fondo de los matraces de degradación no se } \\
\text { observan residuos del b-XgT. En el Ctrl (-) y Ctrl de MM no se } \\
\text { observó alteración alguna. }\end{array}$ \\
\hline \hline & Fuente: Elaboración propia.
\end{tabular}

Fuente: Elaboración propia.

A partir de los resultados de degradación obtenidos, evidenciados en la Fig. 2, se dio inicio el proceso de conteo bacteriano.

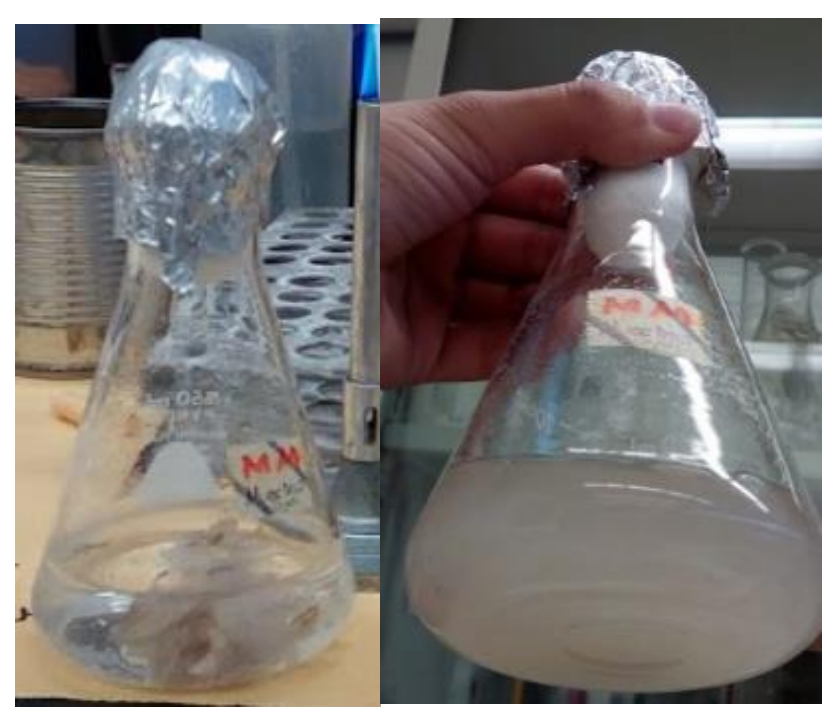

Fig. 2. Degradación de la muestra de b-XgT en MM. Cambio del b-XgT día 1 (izq.) y día 5 (der.).

Fuente: Elaboración propia.

\section{E. Conteo bacteriano}

Se obtuvo carácter incontable de los duplicados de las diluciones $1 * \times 10^{-8}$ y $1 * \times 10^{-9}$ (>300 colonias), por lo que se tuvo en cuenta únicamente el resultado del duplicado de la concentración de $1 * \times 10^{-10}$, los cuales fueron $1,99 \times 10^{12}$ $\mathrm{UFC} / \mathrm{mL}$ y $2,31 \times 10^{12} \mathrm{UFC} / \mathrm{mL}$, en promedio, $2,15 \times 10^{12} \mathrm{UFC}$ por $\mathrm{mL}$ de muestra. El resultado importante para analizar es la viabilidad celular del consorcio bacteriano extraído de los biorreactores de compostaje y suspendidos en MM en un sistema de degradación de condiciones distintas, esto con un límite de detección adecuado [10]. Se reconocieron las células viables cuando a un MM se le añaden los nutrientes adecuados para el desarrollo microbiano, es decir, el b-XgT como fuente de carbono.

\section{F. Actividad bacteriana de la muestra}

Se observó un estado inicial con cerca de 6 morfologías coloniales distintas, por lo que puede afirmarse que las bacterias del aire circundante del laboratorio pudieron alojarse en la superficie del b-XgT. Por otro lado, debido a que las bacterias hacen parte de la flora normal del ser humano, que puede variar entre 100 especies distintas de microorganismos y en su interior albergar hasta 100 trillones [11], con un posible contacto directo se pud explicar la variedad de colonias observadas.

\section{G. Actividad bacteriana en los sistemas de composteo}

Se observaron resultados positivos de amilasa, caseinasa y lecitinasa a diferencia del biorreactor que contenía polietileno. Esto puede relacionarse con las células viables de los biorreactores. También, se tiene en cuenta que las bacterias termófilas poseen variedad enzimas (además de membranas especializadas) que les permiten hacer sus procesos funcionales; se reconocen en especial las amilasas con aplicaciones industriales, como la degradación de polímeros [12]. Igualmente, se observaron morfologías coloniales 
completamente distintas al comparar los medios AA, LD, BP, respectivamente de $\mathrm{M}_{1}$ y $\mathrm{M}_{2}$.

\section{DISCUSIÓN}

Los resultados de la siembra primaria en agar sangre, por un lado, apuntan al daño biológico a los eritrocitos y la apoptosis (Sayed, Kataoka, Oda, Kashiwada, \& Mitani, 2018), pero por otro, revelan la existencia de biosurfactantes (BS) secretados por las bacterias. Los BS en componentes como el suelo y compost, son capaces de degradar sustancias hidrofóbicas, propiedad del copolímero analizado de b-XgT. Los BS de origen bacteriano se originan principalmente por los géneros Pseudomonas, Acinetobacter, Bacillus y Arthrobacter (Becerra \& Horna, 2016; De la Rosa, Sánchez-Salinas, \& Ortiz-Hernández, 2014).

En las bacterias que tuvieron desarrollo en agar Sabouraud se reconocen sus aplicaciones biotecnológicas puesto que cuentan con enzimas como amilasas, proteasas, ligasas, celulasas, que pueden romper los enlaces de polímeros como $\mathrm{b}-\mathrm{XgT}$ e igualmente, pueden relacionarse con organismos termoacidófilos pues los biorreactores se encontraban a $58{ }^{\circ} \mathrm{C}$ y en ellos, se reconoce su capacidad de degradar polímeros [13]

Existen condiciones diferenciadoras que pueden favorecer el crecimiento fúngico o bacteriano, por ejemplo, cuando se disminuye el $\mathrm{pH}$ y se aumenta el $\mathrm{N}$, predominan los hongos, pero, cuando se mantiene un $\mathrm{pH}$ neutro y una relación $\mathrm{C} / \mathrm{N}$ alta, tal como fueron manipuladas las condiciones para el estudio de biodegradabilidad del b-XgT en biorreactores de compostaje, las bacterias son dominantes y en general, la muerte fúngica en procesos de composteo se da a partir de temperaturas de $50{ }^{\circ} \mathrm{C}$ [14].

Como se evidenció en la Tabla III, la morfología celular es predominante de bacilos, lo que es correspondiente a los estudios de biodegradación en compostaje en los que se han identificado filos como Proteobacteria, Actinobacteria, Bacteroidetes y Firmicutes, y a nivel de género, Bacillus sp. emergió como el filotipo más dominante, el cual participa en el ciclado de nutrientes, como $\mathrm{P}, \mathrm{K}, \mathrm{N}, \mathrm{Mn}$, entre otros presentes en la composta [15].

Organismos como Bacillus subtilis son reconocidos por su potencial para utilizar el polietileno (PE) como fuente de carbono, a través de biosurfactantes extracelulares; Bacillus amyloliquefaciens también degrada polietileno de baja densidad (LDPE) por sus medios extracelulares. Por otro lado, especies como Bacillus sterothermophilus poseen $\beta$-xilosidasa y el género Bacillus sp. en general produce xilanasas en espacios termofílico, y a temperaturas de $40-45{ }^{\circ} \mathrm{C}$, lo que corresponde a las condiciones de la prueba de biodegradabilidad [16]. Se sugiere, por tanto, que Bacillus $s p$. es capaz de degradar el b-XgT, teniendo en cuenta también que los consorcios de bacterias se reconocen por la capacidad de la degradación de plásticos [17].

En cuanto a los microorganismos gramnegativos, se han investigado variedad de bacterias que degradan polímeros, como las familias Enterobacteriaceae: Escherichia coli,
Enterobacter asburiae, Serratia marcescen y de la familia Vibrionaceae sp., del género Pseudomona sp., como $P$. aeroginosa, específicamente $P$. Fluorescens y $P$. putida [18]. El género Staphylococcus sp. también participa en la degradación de LDPE con eficiencias de hasta el $22 \%$ [19]. Dichos organismos pueden corresponder a los gramnegativos encontrados en este estudio.

En cuanto a la actividad enzimática evidenciada, dentro de la producción de amilasas, se pueden destacar las $\alpha$-amilasas, $\beta$-amilasas y glucoamilasas, las cuales catalizan la hidrólisis del almidón y carbohidratos relacionados mediante ruptura aleatoria de la unión glicosídica interna oligosacáridos; también catalizan la transglicosilación, condensación y ciclación, puede ser una de las más variadas de todas las glucósido hidrolasas por lo que es reconocida nivel industrial y en el manejo de residuos sólidos [20]. Por tanto, se reconoce que pueden hacer parte de la degradación de b-XgT.

Entre las bacterias más reconocidas por la producción de amilasas relacionadas con la degradación de polímeros como el almidón y por tanto del b-XgT se encuentran Bacillus subtilis, B. staerothermophilus, B.s amyloliquefaciens, B. licheniformis, B. acidocaldarius, Bifidobacterium bifidum, Bifidobacterium acerans [20], Bacillus subtilis, Pseudomonas florescens, E. coli y Serratia marscens [21].

La producción de caseinasa por parte de las bacterias consiste en la capacidad de generar enzimas extracelulares que hidrolizan principalmente proteínas, y con ello transportarlos al interior de la célula en forma de monómeros (los aminoácidos) que les permiten crecer. Esto, pudo ser de utilidad para reconocer la capacidad de enzimas extracelulares del consorcio bacteriano para aprovechar fuentes complejas de carbono como las proteínas.

En la presencia de lecitinasa, una fosfolipasa secretada por las bacterias grampositivas, se pudo destacar que además, sus átomos confieren estabilidad excepcional al calor, es decir, una condición favorable para el aprovechamiento de proteínas en suelo o compost; además, estudios demuestran la movilización de nutrientes como nitrógeno y fósforo por parte de las bacterias a través de la lecitinasa [22].

La lecitinasa se ha identificado en cepas de Pseudomonas sp., Delftia lacustris, Serratia plymuthica, Acinetobacter lwoffii, Baciluus cereus, B. Fordii, entre otras [23]. Por esta razón se puede afirmar que la cepa de nombre ' 1 ' tiene la capacidad de movilizar nutrientes fosfóricos, es decir, permitió que los nutrientes esenciales presentes en el compost pudieran ser asimilados por el consorcio bacteriano.

Se resalta el papel de las enzimas en la biodegradación, ya que a partir de estas, los microorganismos obtienen energía al catalizar las reacciones que involucran la ruptura de enlaces químicos, transfierendo electrones de la sustancia problema. Durante el proceso anaeróbico de los sistemas de composteo, los organismos usaron nitratos, sulfatos, metales, $\mathrm{CO}_{2}$ liberado en las reacciones para obtener electrones que pudieran degradar el b-XgT, habilitando los monómeros como fuente de energía utilizable; una bacteria puede sintetizar o activar constantemente todas las enzimas requeridas para la 
degradación, metabolizar cuando amerite y sea termodinámicamente favorable, lo cual es regulado por los factores físicos y químicos del entorno, variando su producción según la especie bacteriana o cepa aislada [24].

Algunas cepas capaces de degradar plásticos convencionales, como se ha venido mencionando, son de Bacillus sp. cuyas proteasas son responsables de la biodegradación [24]. Por esto, las enzimas adquieren especial atención y es adecuado estudiarlas. Entre las enzimas adecuadas para la detección de actividad enzimática extracelular en las bacterias, se encuentran la caseína, quitinasas, xilasas y lipasas, en donde las provenientes de Bacillus sp. termofílicos, juegan un papel importante en la degradación de plásticos [17].

En general, las exoenzimas más abundantes en aislamientos bacterianos provenientes del suelo y compost son la caseinasa seguida de la amilasa [8], lo que fue congruente con este estudio, en lo que cabe aclarar que aquellas cepas que no presentaron ningún desarrollo en los medios AA, LD y BP, pueden generar actividad de otro tipo de enzimas. Por tanto, la complejidad bacteriana proveniente del inóculo de compost de los biorreactores, permitió la erosión y degradación hidrolítica del b-XgT, aspecto evidenciable por los subproductos como monómeros, $\mathrm{CO}_{2}, \mathrm{CH}_{4}, \mathrm{H}_{2} \mathrm{O}$, y el desarrollo enzimático [25].

Finalmente, en cuanto al conteo bacteriano, se comprende que el resultado de $2,15 \times 10^{12} \mathrm{UFC} / \mathrm{mL}$ es positivo al comparar con estudios de biofertilizantes y aceleradores de composteo cuya mayor tasa de crecimiento bacteriano a las $24 \mathrm{~h}$ fue de $2 \times 10^{12} \mathrm{UFC} / \mathrm{mL}$ [26]. Otro espacio de análisis son las 'formulaciones de bacterias', encontradas en el mercado como alternativas para el desarrollo bacteriano funcional; se describe que un consorcio de bacterias facultativas del género Bacillus de $2 \times 10^{12} \mathrm{UFC} / \mathrm{mL}$, es una tasa adecuada [27].

Por tanto, el desarrollo bacteriano en MM cuando el b-XgT es fuente de carbono de un consorcio bacteriano proveniente de un ensayo de degradación en biorreactores de compost, genera una densidad bacteriana alta.

\section{CONLUSIONES}

- Las características de los microorganismos participantes en la degradación del b-XgT durante la prueba de biodegradabilidad en biorreactores de compostaje en condiciones controladas de laboratorio, son principalmente bacterias grampositivas de morfología bacilar (14 de las 16 bacterias desarrolladas), las cuales se encontró que participaron en diversidad de investigaciones en la degradación de bioplásticos con el género Bacillus sp.. También, se encontró la existencia de bacterias con capacidad secretar biosurfactantes, sustancias hidrófobas capaces de degradar sustancias hidrofóbicas, característica del b-XgT. Durante la digestión anaerobia del bioplástico analizado, también se desarollaron organismos acidófilos de tipo extremófilo facultativo, los cuales también son reconocidos por su capacidad de erosionar sustancias poliméricas y asimilarlas en su estructura celular.
- Se analizó la capacidad de excretar enzimas que permitieran aprovechar las fuentes de carbono disponibles por las bacterias de este estudio. Se encontró actividad de amilasa, caseinasa y lecitinasa positiva por algunas de las bacterias aisladas en este estudio. Al corresponder a una evaluación de proteasas, son coherentes con estudios que demuestran que estas enzimas permiten a los organismos degradar polímeros. Por otro lado, cuando se evaluó el consorcio bacteriano proveniente del biorreactor de compostaje que comprobó la biodegradabilidad del b-XgT, se tuvo un resultado positivo de amilasa, caseinasa y lecitinasa, a diferencia de varias de las cepas bacterianas aisladas en la siembra secundaria, por lo cual, se soporta que la sinergia de las comunidades microbianas aumenta la capacidad de degradación en todo el medio.

- Se encontró que cuando se introduce b-XgT como fuente de carbono en biorreactores de compostaje, las comunidades bacterianas poseen una viabilidad celular alta, pues a través del recuento en placa se encontró una densidad de 2,15 x $10^{12}$ $\mathrm{UFC} / \mathrm{mL}$ de muestra. Esto, fue respaldado al observar la rápida erosión de la muestra de b-XgT cuando se sometió a medio mineral como medio líquido que permitiera evidenciar su deterioro y asimilación por los microorganismos. Se reconoció que la degradación del b-XgT en compost anaerobio permite una alta viabilidad microbiana aprovechable como abono.

\section{DECLARACIÓN DE CONFLICTO DE INTERESES}

Los autores declaran no tener ningún conflicto de intereses relacionado a este artículo científico.

\section{AGRADECIMIENTOS}

Se expresa especial agradecimiento al Ph. D. Alfredo Maciel por la donación del b-XgT; al Ph.D. Luciano Hernández y a Laura Mauricio del Laboratorio de Microbiología Experimental de la Universidad Nacional Autónoma de México.

\section{REFERENCIAS}

[1]. N. K. Kalita, S. M. Bhasney, C. Mudenur, A. Kalamdhad, y V. Katiyar, "End-of-life evaluation and biodegradation of Poly(lactic acid) (PLA)/Polycaprolactone (PCL)/Microcrystalline cellulose (MCC) polyblends under composting conditions", Chemosphere, vol. 247, p. 125875, ene. 2020. DOI: https://doi.org/10.1016/j.chemosphere.2020.125875.

[2]. S. M. Emadian, T. Onay, y B. Demirel, "Biodegradation of bioplastics in natural environments", Waste Manag., vol. 59, pp. 526-536, ene. 2017. DOI: https://doi.org/10.1016/J.WASMAN.2016.10.006.

[3]. L. García, J. Novoa, A. Franco, y L. Higuita, "Estudio de la síntesis de biopolímeros de origen microbiano", $Q U I D$, vol. 25, pp. 69-78, 2015.

[4]. D. Adamcová, J. Zloch, M. Brtnický, y M. D. Vaverková, "Biodegradation/Disintegration of Selected Range of Polymers: Impact on the Compost Quality", J. Polym. Environ., vol. 27, núm. 4, pp. 892-899, abr. 2019. DOI: https://doi.org/10.1007/s10924019-01393-3.

[5]. V. Bátori, D. Åkesson, A. Zamani, M. J. Taherzadeh, y I. S. Horváth, "Anaerobic degradation of bioplastics: A review", 2018. DOI: https://doi.org/10.1016/j.wasman.2018.09.040.

[6]. Neogen, "STANDARD METHODS AGAR (7157)", 2018.

[7]. N. Rijal, "Sabouraud Dextrose Agar (SDA): Principle, 
composition, uses and colony morphology - Microbeonline", Microbeonline | Medical Microbiology Guide, 2015. [En línea]. Disponible en: https://microbeonline.com/sabouraud-dextroseagar-sda-principle-composition-uses-colony-morphology/. [Consultado: 23-abr-2019].

[8]. P. Diniz, F. de Faria, S. Facchin, C. Rebello, J. Netto, y E. Kalapothakis, "Survey of Microbial Enzymes in Soil, Water, and Plant Microenvironments", Open Microbiol. J., vol. 8, p. 25, 2014. DOI: https://doi.org/10.2174/1874285801408010025.

[9]. M. Fields, "The Flat Sour Bacteria", en Advances in Food Research, Chichester, Mrak, y Stewart, Eds. New York: Academic Press, 1970, pp. 164-208.

[10]. E. Sánchez, D. Núñez, R. Cruz, M. Torres, y E. Herrera, "Simulación y Conteo de Unidades Formadoras de Colonias", Rev. electrónica Comput. Informática, Biomédica y Electrónica, vol. 6, núm. 1, 2017.

[11]. L. Solano, "Epidemiología de Bacterias Anaerobias Aisladas en Muestras Clínicas en el Hospital San Juan De Dios, San José, Costa Rica, Durante el Trienio 2014, 2015 Y 2016", Rev. Costarric. Salud Pública, vol. 27, núm. 2, pp. 82-92, 2018.

[12]. M. Porfiri, N. Melnichuk, M. Braia, C. Brinatti, W. Loh, y D. Romanini, "Analysis of the structure-function relationship of alpha amylase complexed with polyacrylic acid", Colloids Surfaces B Biointerfaces, vol. 188, p. 110787, 2020. DOI: https://doi.org/10.1016/j.colsurfb.2020.110787.

[13]. A. Sharma, Y. Kawarabayasi, y T. Satyanarayana, "Acidophilic bacteria and archaea: acid stable biocatalysts and their potential applications", Extremophiles, vol. 16, núm. 1, pp. 1-19, ene. 2012. DOI: https://doi.org/10.1007/s00792-011-0402-3.

[14]. A. Silva-Sánchez, M. Soares, y J. Rousk, "Testing the dependence of microbial growth and carbon use efficiency on nitrogen availability, $\mathrm{pH}$, and organic matter quality", Soil Biol. Biochem., vol. 134, pp. 25-35, jul. 2019. DOI: https://doi.org/10.1016/j.soilbio.2019.03.008.

[15]. W.-Y. Huang et al., "Aerobic co-composting degradation of highly PCDD/F-contaminated field soil. A study of bacterial community", Sci. Total Environ., vol. 660, pp. 595-602, abr. 2019. DOI: https://doi.org/10.1016/j.scitotenv.2018.12.312.

[16]. P. Vimala y L. Mathew, "Biodegradation of Polyethylene Using Bacillus Subtilis", Procedia Technol., vol. 24, pp. 232-239, 2016. DOI: https://doi.org/10.1016/j.protcy.2016.05.031.

[17]. T. C. H. Dang et al., "Plastic degradation by thermophilic Bacillus sp. BCBT21 isolated from composting agricultural residual in Vietnam", Adv. Nat. Sci. Nanosci. Nanotechnol., vol. 9, núm. 1, p. 015014, mar. 2018. DOI: https://doi.org/10.1088/20436254/aaabaf

[18]. N. Acuña Molina, "Revisión Bibliografica Sobre los Microorganismos Biodegradadores de Polietileno de Baja Densidad y Sus Efectos en el Material", Universidad Distrital Francisco José De Caldas, 2017.

[19]. M. Raziyafathima, P. Praseetha, y R. Rimal Isaac, "Microbial Degradation of Plastic Waste: A Review", J. Pharm. Chem. Biol. Sci., vol. 4, núm. 2, pp. 231-242, 2016.

[20]. M. A. Naidu y P. Saranraj, "Bacterial Amylase: A Review", Int. J. Pharm. Biol. Arch., vol. 4, núm. 2, pp. 274-287, 2013.

[21]. S. S. Alariya, S. Sethi, S. Gupta, y L. Gupta, "Amylase activity of a starch degrading bacteria isolated from soil", 2013.

[22]. N. Ramarao, D. Lereclus, y A. Sorokin, "The Bacillus cereus Group", Mol. Med. Microbiol., pp. 1041-1078, ene. 2015.

[23]. É. Tamás, G. Mara, I. Máthé, É. Laslo, É. György, y S. Lányi, "Isolation, Characterization And Identification Of Nitrogen And Phosphorus Mobilizing Bacteria", Environ. Eng. Manag. J., vol. 11, núm. 3, pp. 675-680, 2012. DOI: 10.30638/EEMJ.2012.085.

[24]. R. Devi et al., "The Role of Microbes in Plastic Degradation", en Environmental Waste Management, CRC Press, 2015, pp. 341370. DOI: $10.1201 / \mathrm{b} 19243-13$.

[25]. Roohi et al., "Microbial Enzymatic Degradation of Biodegradable Plastics", Curr. Pharm. Biotechnol., vol. 18, núm. 5, pp. 429-440, jul. 2017. DOI: 10.2174/1389201018666170523165742.

[26]. P. Martínez, J. Bernal, M. Calixto, M. A. Del Basto, y B. Chaparro, "Biofertilizers And Composting Accelerators Of Polluting Macrophytes Of A Colombian Lake", J. soil Sci. plant Nutr., vol. 11, núm. 2, pp. 47-61, 2011. DOI: http://dx.doi.org/10.4067/S0718-95162011000200005.
[27]. Agro Q-tral, “Aquam”, Agro Q-tral | CPOThemes, 2019. [En línea]. Disponible en: https://agroq-tral.aqt.cl/aquam/. [Consultado: 21-may-2019].

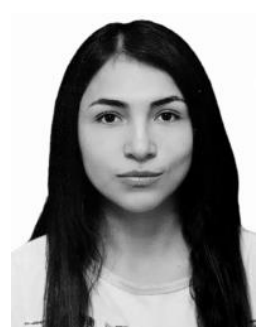

Paola A. Álvarez-Betancourt, nació en Bogotá, Colombia, en 1996. Recibió su título de ingeniera ambiental en el año 2019 en la Universidad Distrital Francisco José de Caldas. Ha tenido experiencia en el área de consultoría ambiental en proyectos de sostenibilidad social, económica y ambiental para el Instituto de Hidrología, Meteorología y Estudios Ambientales. Ha trabajado en consultoría ambiental para entidades privadas y apoyando el uso de herramientas de Sistemas de Información Geográfica-SIG- para el cumplimiento de los requerimientos técnicos de los procesos de licenciamiento ambiental. En su proceso de movilidad académica a la Universidad Nacional Autónoma de México realizó la instancia investigativa en el Laboratorio de Microbiología Experimental de la Facultad de Química.

ORCID: https://orcid.org/0000-0002-2295-402X

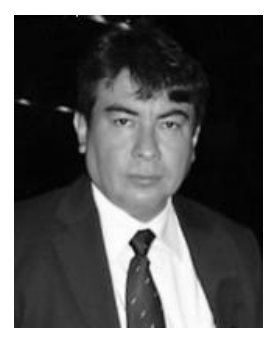

Víctor M. Luna-Pabello, es Biólogo, con Maestría y Doctorado en Biología de la Universidad Nacional Autónoma de México, de Ciudad de México, México. Acreedor a la medalla de plata "Gabino Barreda" por estudios de doctorado y a la beca "Marie Curie", proporcionada por la Comunidad Económica Europea para su estancia posdoctoral en el Instituto Nacional de Ciencias Aplicadas de Toulouse, Francia, trabajando en el área de ecología microbiana de sistemas de tratamiento de aguas residuales. Tiene 24 años de experiencia en el tratamiento biológico de aguas residuales domésticas e industriales

Actualmente, es Profesor de Carrera Titular "C" de tiempo completo definitivo, PRIDE "C", SNI nivel I, adscrito al Laboratorio de Microbiología Experimental del Departamento de Biología de la Facultad de Química de la UNAM dirigiendo materias de pregrado y posgrado. Dirige un grupo de investigación sobre ecología microbiana aplicada a la depuración de aguas y suelos contaminados orgánicamente. Es tutor para alumnos de Maestría y Doctorado de los Posgrados en Ciencias Biológicas, Ciencias Bioquímicas, Ingeniería (Ingeniería Ambiental) y Ciencias del Mar y Limnología.

Ha sido responsable y corresponsable en diversos proyectos de investigación financiados por el CONACYT, DGAPA, PUMA, Comunidad Económica Europea e IMP. Coordina al Grupo Académico Interdisciplinario Ambiental de la Facultad de Química, donde participa personal académico de diversas dependencias de la UNAM que brinda servicios, para industrias paraestatales y del sector privado, relacionados con estudios de impacto y riesgo ambiental. Cuenta con una 
patente sobre humedales artificiales y una más se encuentra en trámite.

ORCID: https://orcid.org/0000-0001-8651-0295

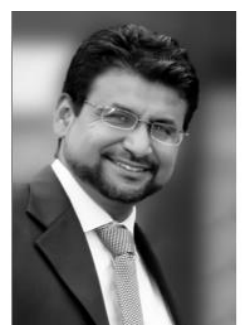

Jaime E. Ussa-Garzón, es ingeniero forestal, especialista en ambiente $y$ desarrollo rural, mágister en desarrollo rural de la Universidad Distrital Francisco José de Caldas (UDFJC) de Bogotá, Colombia. Ha sido docente de planta de los pregrados de ingeniería ambiental e ingeniería forestal por más de 17 años de asignaturas como tecnologías apropiadas, manejo técnico ambiental, sistemas agroforestales, ecología, ordenamiento territorial, entre otras.

Ha sido catedrático de posgrado de la Universidad Manuela Beltrán, Universidad del Tolima y de la UDFJC. Ha sido director de más de setenta trabajos de grado aplicados de ingeniería ambiental y forestal y especialización en ambiente y desarrollo local. A su vez, ha sido panelista y ponente de distintos foros relacionados con las tecnologías apropiadas, las fuentes alternativas de energía, sobre la innovación en la educación técnica, tecnológica y de ingeniería.

Su labor investigativa se ha basado principalmente en el desarrollo rural a partir de propuestas basadas en el desarrollo forestal sostenible con base en productos forestales no maderables, así como estudios de determinación de módulos agroforestales, agroredes, caracterización de unidades productivas y propuesta de modelos agroforestales con aplicación en distintos municipios de Colombia. Asimismo, en propuestas de producción agroindustrial para el desarrollo alternativo, conceptualización de sistemas integrados de producción agropecuaria, guías de sondeos de mercado local para microempresas locales y valoración económica de pasivos ambientales.

Tiene experiencia laboral de cerca de 20 años en la aplicación de la ingeniería en planes de manejo, gestión ambiental, coordinando o dirigiendo proyectos de evaluación del riesgo, evaluación de la calidad del aire, trámites de permisos de aprovechamiento forestal, en la evaluación ambiental, valoración económica de proyectos. Ha realizado trabajos de campo para el levantamiento de información primaria para el mapeo de amenazas por incendios forestales, actualización de estudios técnicos; ha coordinado proyectos de caracterización rural, actualización de renovación de registros calificados ante el Ministerio de Educación de Colombia; también ha orientado la conformación, capacitación y formación de redes de oferentes de alimentos.

Trabajó con el PNUD como consultor externo en gerencia de planes de acción de gestión social, así como en la gestión de recursos ante la Unión Europea para la consolidación de núcleos productivos. Ha sido consultor externo en procesos agroindustriales para el manejo ambiental de cuencas hidrográficas.
ORCID: https://orcid.org/0000-0002-5138-8119 